UCRL-JC-122534

CONEFRINT $960204--5$

\title{
Ultrahigh Carbon Steel for Automotive Applications
}

\author{
D. R. Lesuer \\ C. K. Syn \\ O. D. Sherby
}

This paper was prepared for submittal to the 1996 SAE International Congress \& Exposition

Detroit, Michigan

February 26-29, 1996

December 4, 1995

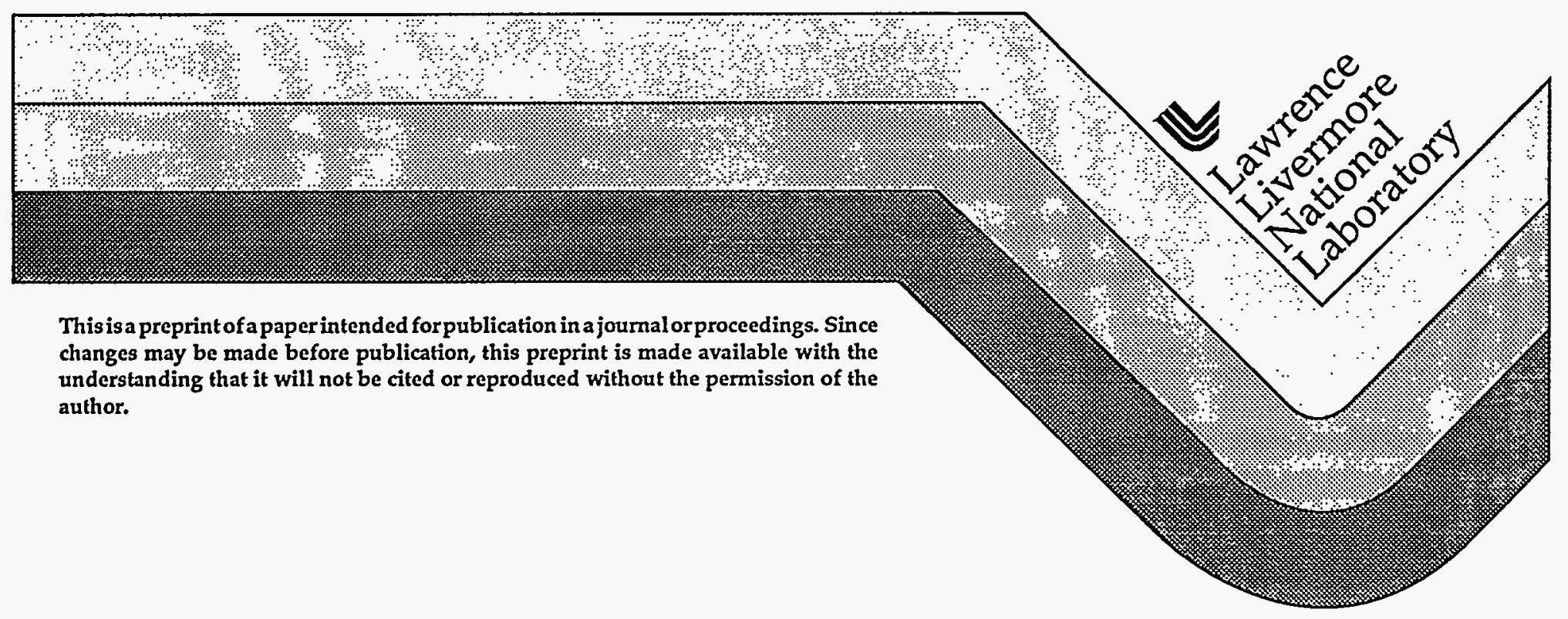

This is a preprint of a paper intended forpublication in a journal or proceedings. Since changes may be made before publication, this preprint is made available with the understanding that it will not be cited or reproduced without the permission of the author. 


\section{DISCLAIMER}

This document was prepared as an account of work sponsored by an agency of the United States Government. Neither the United States Government nor the University of California nor any of their employees, makes any warranty, express or implied, or assumes any legal liability or responsibility for the accuracy, completeness, or usefulness of any information, apparatus, product, or process disclosed, or represents that its use would not infringe privately owned rights. Reference herein to any specific commercial product, process, or service by trade name, trademark, manufacturer, or otherwise, does not necessarily constitute or imply its endorsement, recommendation, or favoring by the United States Government or the University of California. The views and opinions of authors expressed herein do not necessarily state or reflect those of the United States Government or the University of California, and shall not be used for advertising or product endorsement purposes. 

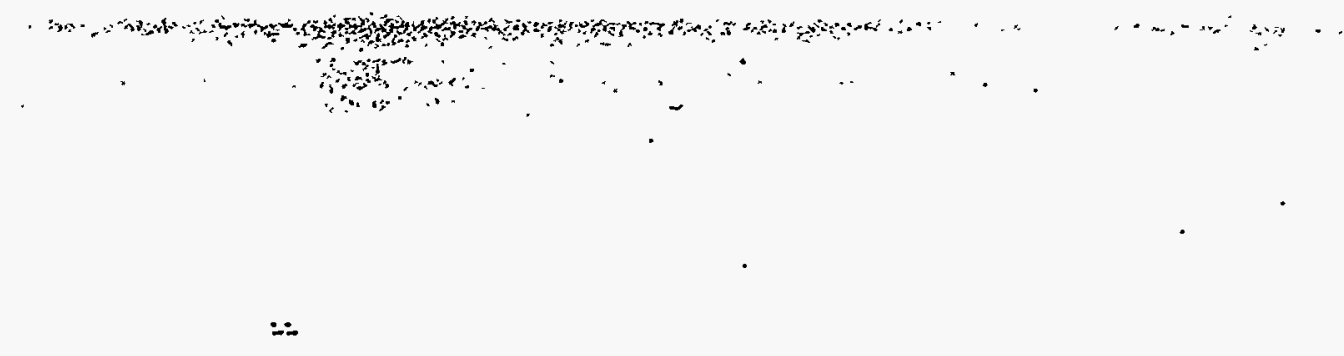

Ultrahigh Carbon Steel for Automotive Applications

\author{
Donald R. Lesuer*, Chol K. Syn* and Oleg D. Sherby** \\ *Lawrence Livermore National Laboratory \\ Livermore, CA 94551 \\ ${ }^{\star *}$ Stanford University \\ Stanford, CA 94305
}

\section{ABSTRACT}

Ultrahigh carbon steels (UHCSs), which contain 1-2.1\% carbon, have remärkable structural properties for automotive application when processed to achieve fine ferrite grains with fine spheroldized carbides. When processed for high room temperature ductility, UHCS can have good tensile ductility but significantly higher strength than current automotive high strength steels. The material can also be made superplastic at intermediate temperatures and exhibits excellent die fill capability. Furthermore, they can be made hard with high compression ductility. In wire form it is projected that UHCS can exhibit extremely high strengths (5000 MPa) for tire cord applications. Examples of structural components that have been formed from fine-grained spheroidized UHCSs are illustrated.

\section{INTRODUCTION}

Ultrahigh-carbon steels (UHCSs) are plain carbon steels with carbon content ( 1 to $2.1 \%$ carbon) beyond the eutectoid composition. These steels, which contain $15-32$ vol.\% iron carbide, have historically been neglected by industry because of a belief that they are inherently brittle. The primary reason for this belief is that brittle proeutectoid carbide networks can be formed along grain boundaries if appropriate processing procedures are not used. However, novel themomechanical processing and heat treatment techniques have been developed at Stanford University and the Lawrence Livermore National Laboratory to break up the carbide network and produce microstructures containing fine equiaxed ferrite grains and uniformly distributed carbides. These steels can possess a unique set of properties, unavailable in other materials, that make them well suited for structural applications [1]. Specifically, UHCSs can have high amblent-temperature strength, hardness and ductility, and excellent high-temperature formability via superplasticity. In this paper we describe the composition and processing of this unique steel, as well as the resulting properties, characteristics and applications that are relevant to the automotive industry.

\section{COMPOSITION AND PROCESSING}

The UHCSs investigated so far contained 1 to 2.1 wt.\% $\mathrm{C}$, and other alloying elements, such as, $\mathrm{Al}, \mathrm{Cr}, \mathrm{Si}$, and $\mathrm{Mn}$ of varying contents. The $\mathrm{Al}$ is added to increase the $A_{1}$ transition temperature, the $C r$ to prevent graphitization, the Si to raise the $A_{1}$ temperature and to inhibit particle carbide growth and the Mn to neutralize the deleterious effects of sulfur and phosphorus.

Various thermomechanical and heat treatment processes have been developed [2-8] to eliminate the proeutectoid carbide network and convert the coarse lamellar pearlitic matrix in the starting material to fine grained ferrite matrix with finely spheroidized carbides. The theimomechanical and heat treatment processes employed include hot and warm working (HWW), 

bide network. The starting UHCS material is heated to the austenite region where carbon is completely dissolved in the austenite iron and then continuously worked by rolling or forging until the material is cooled below the $A_{1}$ temperature. The hot working in the austenite region refines-the austenite grain size and the subsequent warm working between the $A_{c m}$ and $A_{1}$ temperatures allows the proeutectoid carbide to precipitate and grow discontinuously on the austenite grain boundaries instead of forming a continuous network. The refined austenite matrix then transforms to pearlite when cooled to room temperature. The HWW'ed microstructure thus consists of the proeutectoid carbides broken down into spherodized proeutectoid carbide particles and a pearlite matrix. The DET process" converts the lamellar carbide in the pearlite matrix to spheroidized carbide. The pearlite structure is heated to a temperature above the $A_{1}$ point, where it is thermodynamically unstable, and most of the carbide rapidly dissolves in iron. The remaining undissolved carbides are finely dispersed and become-spherical rapidly. The dissolved carbon atoms are non-uniformly distributed, at least for a short while, in the regions where the pearlitic carbides originally existed. During cooling, the undissolved carbides and non-uniform distribution of carbon act as sites for nucleation and growth of carbides and results in a fine, uniform carbide distribution with no pearlite formed. The DETWAD process accolerates the DET process by using concurrent deformation, increasing the extent of spherical carbide formation and refining the ferrite grain size. The concurrent deformation begins just above the pearlite - dissolution temperature and continues as the material cools through the $A_{1}$ temperature. Combination of these processes can produce submicron sized ferrite grains and spheroidized carbides.

The spheroidized carbide and equiaxed ferrite grain structure can be transformed to pearlite, bainite, or martensite in ultrafine structure form, or their combinations through appropriate thermal or themomechanical processing methods for further strength or other property advantages.

\section{ULTRAHIGH STRENGTH STEEL SHEET AND PLATE}

PROPERTIES - Sheet steels based on ultrahighcarbon contents represent a new and unique approach which is opposite to the current trend in steels. Specifically, over the last thirty years, the carbon content in commercially available sheet steels has been decreasing [9]: The ultralow-carbon steels that are currently available have been developed primarily for automotive sheet-stamping applications in which high formability and weldability are of paramount importance.

mechanisms, using solid-solution and preciptation hard-

ening rapproaches, have tbeen required to tachioven improved strength. The welding problem that exists in low and medium carbon steels may not exist in UHCS because the metallurgy of transformation is so dramatically different from that observed in low carbon steels.

An example of spheroidized microstructures and the corresponding room temperature stress-strain curves for a UHCS-1.8\% C-1.6\% Al material is shown in Fig. 1. Micrograph (a) shows large ferrite grains $(\sim 3.5 \mu \mathrm{m}$ grain size) and large carbides (average carbide size -about 1 $\mu \mathrm{m}$ at grain boundaries and about $0.8 \mu \mathrm{m}$ in the grain interiors). At the other extreme, micrograph (d) shows a very fine spheroidized structure that has a mean carbide size at grain boundaries and a mean ferrite grain size of about $0.3 \mu \mathrm{m}$, with a mean carbide size in grain interiors of $0.22 \mu \mathrm{m}$. The finest microstructure shown in micrograph (d) corresponds to the stress-strain curve (d) that has the highest yield strength (1470 MPa) but the lowest total elongation (2.2\%). The coarsest structure (a) corresponds to curve (a), which shows the lowest yield strength $(780 \mathrm{MPa})$ but the highest total elongation (25\%). Syn, Lesuer and Sherby [10] have shown that the yield strength of the spheroidized UHCS-1.8\% C$1.6 \%$ Al material is a unique function of the grain size and grain interior carbides, while the fracture strength is a unique function of the carbide particle size at grain boundaries and the carbide strength [11]. Room tem-

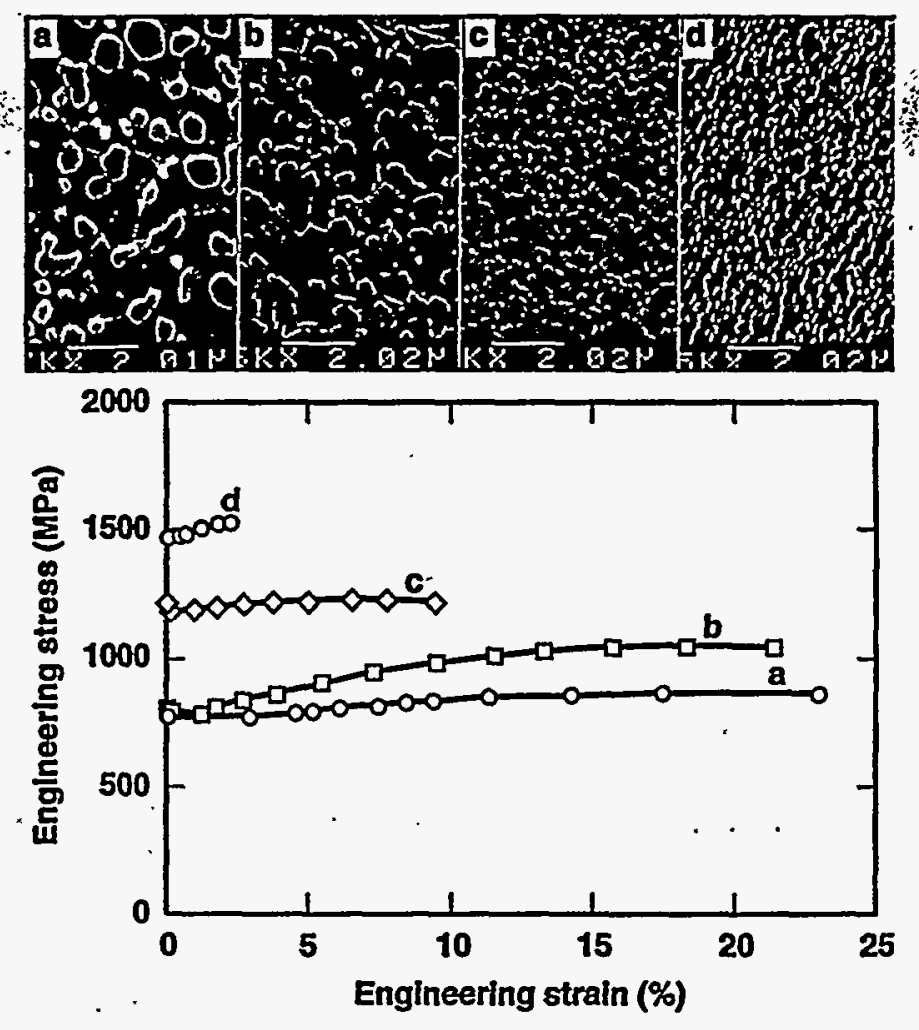

Figure 1. Micrographs of UHCS and corresponding stressstrain curves. The UHCS has been processed to various equiaxed ferrite grain sizes and spheroldized carbldes. 
perature properties of other UHCS

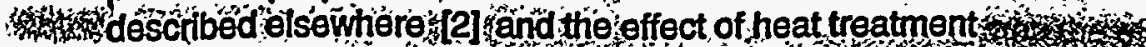

is covered in a subsequent section.

APPLICATIONS ' For sheet/thin plate applications high strength and good cold-stamping characteristics are often required. UHCSs are a logical material substitution for high-strength sheet components that are strength limited rather than stiffness limited. The primary driver for high-s'trength steels in automotive sheet applications is often weight reduction which results in enhanced performance and fuel econority.

In Fig. 2 the tensile true stress - true strain curve for UHCS processed for high ambient temperature ductility (coarse ferrite grains and fine carbides at the grain boundaries) is compared with the tensile behavior of four steels suitable for automotive applications. The data for these four steels was obtained from reference 12 . One of the steels in Fig. 2 is a plain, low carbon steel with properties representative of steels currently used in cold stamping operations. The remaining three steels are dual phase steels with properties representative of the so-called high strength steels. As can be seen the UHCS has comparable tensile elongation to the other steels; however, it has significantly higher yield and flow stress. The formability of UHCS has not been evaluated; however, the high tensile ductility and high work hardening rate of this material, as shown in Fig. 2, suggests that, in the appropriate microstructural condition, UHCS can have forming limits as good as the dual phase steels shown in the figure.

Another important characteristic of UHCS is that the material retains its high strength at typical tempering temperatures. This property is important for elevated temperature-high strength; applications such as high strength clutch plates, where a loss in strength would occur in martensite-containing steels. The UHCS materials described here retain their strength at tempering temperatures because the ferrite-carbide microstructures are stable.

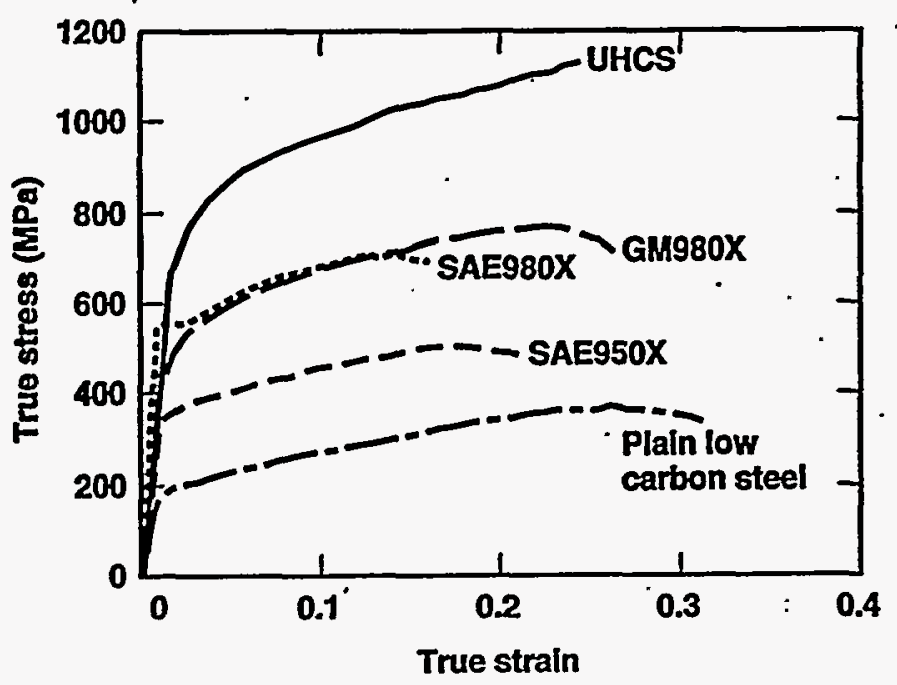

Figure 2. Comparison of the tensile stress-strain behavior of UHCS and four other-steels suitable for automotive applications. The UHCS has been processed for high room temperature ductility.
One of the biggest advantages of the tine-grained UHCS reported here is the opportunity for net shape forming using superplasticity $[2,13]$. Because of the fing grain sizes developed in these materials, elongations in excess of $600 \%$ have been obtained in plain-carbon UHCSs at warm-working temperatures [14,15]. For plain-carbon and dilute-alloyed UHCSs, the range of temperature and composition over which superplasticity has been observed is shown on the Fe-C phase diagram in Figure 3. Grain sizes evaluated were typically around $2 \mu \mathrm{m}$. For the UHCS-composition range $(1.0-2.1 \% \mathrm{C})$, superplasticity can be observed at temperatures from $650^{\circ} \mathrm{C}-800^{\circ} \mathrm{C}$. This temperature range extends above and below the $A_{1}$ transformation temperature and thus includes microstructures containing ferrite and carbides or austenite and carbides. The carbides help maintain a fine-grained microstructure, by pinning the grain boundaries and retarding the grain-growth kinetics. In the austenite-plus-carbide region, the maximum temperature for superplasticity is determined by grain growth kinetics and the loss of the fine-grained microstructure. Grain growth is rapid in the austenite-plus-carbide region because much of the carbide that is present in the initial ferrite-plus-carbide structure is lost due to the high solubility of carbon in austenite. Superplastic behavior has also been achieved with carbon contents in excess of $2.1 \% \mathrm{C}$ (Fig. 3 ). These are the cast irons $(2.1 \%-4.3 \% \mathrm{C}$ ) and hypereutectic irons $(5.25 \% \mathrm{C})$ [16-19]. For hyporeutectic irons, the matrix is iron carbide with discontinuous ferrite. The fine equiaxed grains required for superplasticity in these materials were prepared by powder. metallurgy routes.

For plain-carbon UHCSs, the maximum strain rate for superplasticity is about $10^{-3} \mathrm{~s}^{-1}$ which is achieved just below the $A_{1}$ transformation temperature [15]. This strain . rate can be increased dramatically through suitable

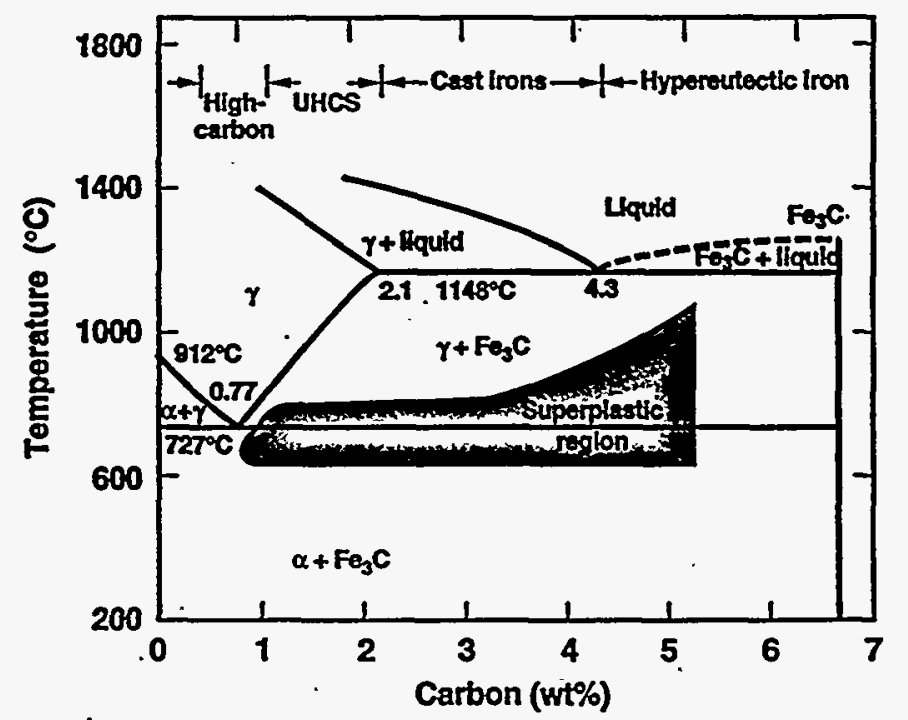

Figure 3. The Fe-C phase diagram showing the reglon of composition and temperature within which superplasticity has been observed in UHCS. 

temperatures within the range of superplastic flow without objectionable amounts of $\mathrm{grain}$ growth $\mathrm{or}$ (b) inhibit the transition from grain-boundary sliding (superplastic - behavior) to slip creep (non-superplastic behavior) by raising the flow stress for slip creep. Higher superplastic-deformation temperatures are obtained with these alloying additions because they influence the characteristics and microstructure of UHCSs in at least one of four ways, by (a) increasing the $A_{1}$ transformation temperature, (b) inhibiting carbide coarsening because the activity of carbon in ferrite is increased, (c) forming complex carbides that resist coarsening, and (d) increasing the amount of proeutectoid carbides.

An example of high strain rate superplasticity in UHCS containing high aluminum content is illustrated in Fig. 4 for UHCS containing 1.5\% C and 10\% Al. The figure shows a sample before and after tensile deformation at $950^{\circ} \mathrm{C}$ and a strain rate of $-3 \times 10^{-2} \mathrm{~s}^{-1}$. At this temperature the material was below the $A_{1}$ transformation temperature. The sample was stretched to an elongation of $1250 \%$ elongation without failure, which, at the strain rates indicated, required approximately 6 minutes to achieve. These results show the excellent potential for these fine-grained materials in high throughput commercial forming operations.

Figure 5 shows the maximum strain rate for super'plasticity as a function of temperature for four different UHCS alloys containing aluminum and silicon $[21,23]$. All materials have a common initial grain size of $2 \mu \mathrm{m}$. UHCSs containing either $3 \%$ Si or $1.6 \%$ Al both exhibit superplastic flow at a maximum strain rate of $10^{-2} \mathrm{~s}^{-1}$, in

$\because$ is the temperature range of $770^{\circ} \mathrm{C} 80^{\circ} \mathrm{C}$. Aluminum appears to be much more effective than silicon in raising the superplastic forming rate. The figure also shows the predicted maximum superplastic-forming rate for a UHCS containing $12 \%$ Al with a grain size of $2 \mu \mathrm{m}$. This material should exhibit a maximum superplastic forming rate of $3 \times 10^{-1} \mathrm{~s}^{-1}$ at $950^{\circ} \mathrm{C}$, which is close to commercial

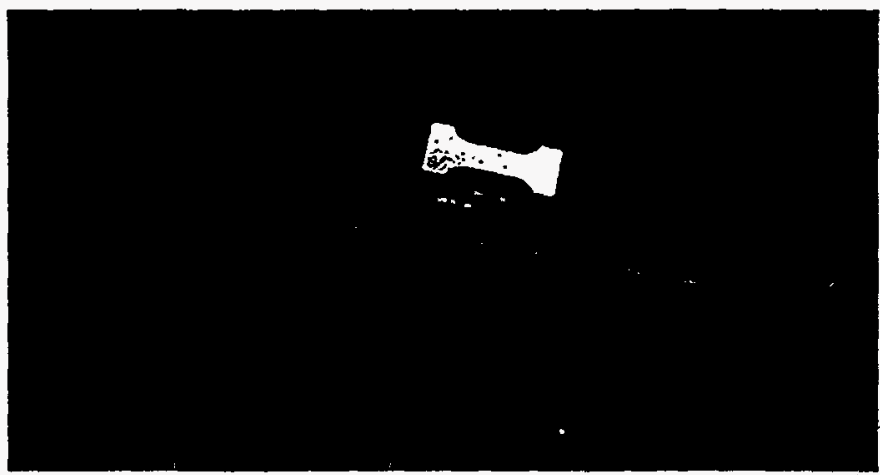

Figure 4. High rate superplasticy in a UHCS-1.5C-10AI alloy. The figure shows a sample before and after tensile deformation at $950^{\circ} \mathrm{C}$ and a strain rate of $.03 \mathrm{~s}-1$. The sample was stretched to an elongation of $1200 \%$ without fracture in approximately 6 minutes.

NET SHAPE PROCESSING - The suiperplastic forming characteristics described in the previous section result from the presence of grain boundary sliding as a deformation mechanism which exhibits high strain rate sensitivity with low flow stress. Forging at temperatures and strain rates where this mechanism is activated can thus produce excellent die fill capacity and the opportunity for net shape processing. The excellent die fill capacity of these materials has been illustrated with the forging of prototype components which will be illustrated in a later section.

PROPERTIES AFTER HEAT TREATMENT - When a UHCS is processed to develop an ultrafine structure, it can then be heat treated to achieve unique microstructures and properties. Examiples are the development of unique martensitic, bainitic and pearlitic structures $[2,8,24,25]$.

Figure 6 lllustrates coarse and fine martensitic structures in a UHCS material containing $1.8 \% \mathrm{C}$ and $1.6 \% \mathrm{Al}$. Figure $6 a$ shows the structure of the UHCS material after water quenching from $1000^{\circ} \mathrm{C}$. At this austenitizing temperature, most of the carbides are dissolved and the austenite grain size is coarse. Thus, the quenched structure is seen to be coarse martensite. Such a coarse martensitic UHCS material, although very hard, does not have any significant compression ductility at room temperature.[24]. When a fine-grained spheroidized struc. ture is achieved, such as that shown in Figure 1, and the material is heated to a low austenitizing temperature (e.g. $810^{\circ} \mathrm{C}$ ) and water quenched, the result is optically unresolvable martensite. An example of the fine martensitic microstructure obtained in the.UHCS-1.8\% C-1.6\% Al material is given in Figure 6b. The SEM micrograph is

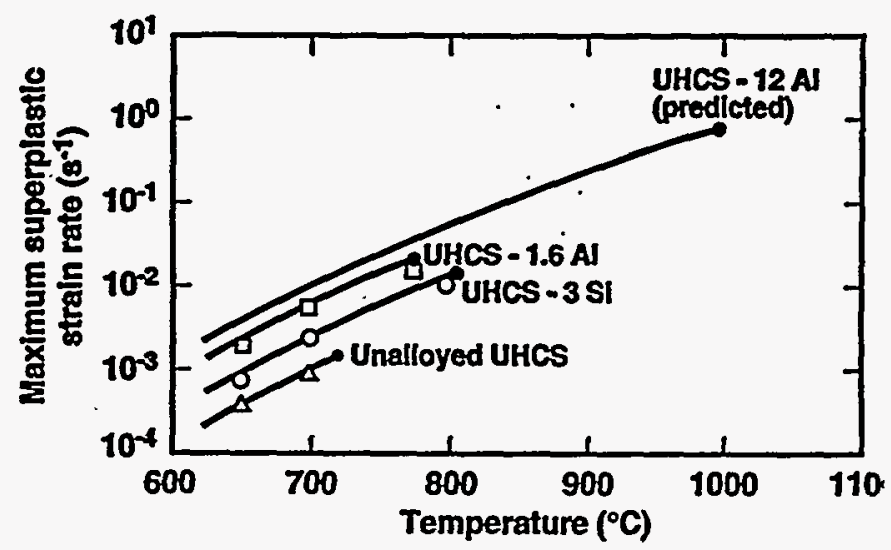

Figure 5 The influence of aluminum and sillicon on the maximum strain rate for superlasticity. The maximum strain rate at the $A_{1}$ temperature is indicated by a solld circle. 


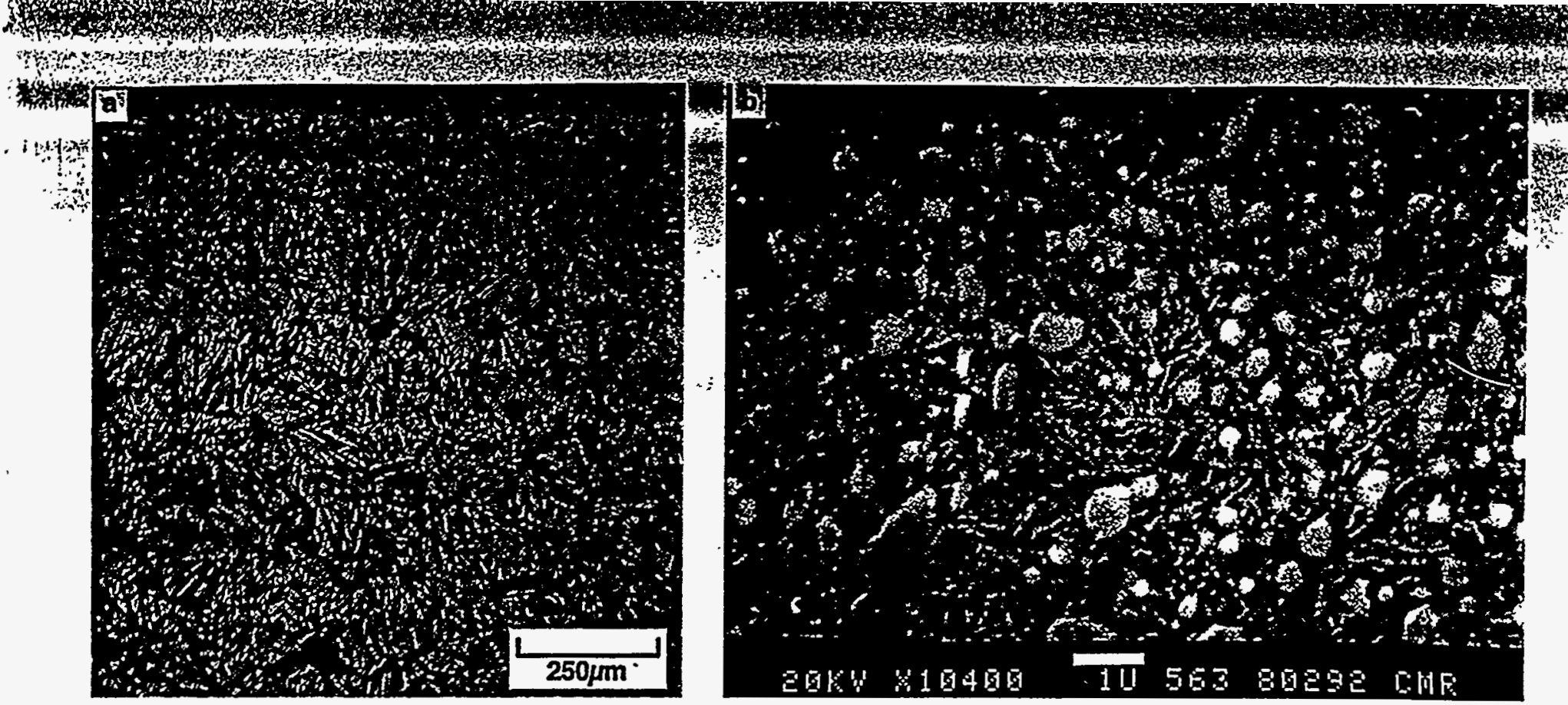

Figure 6 (a) Optical photomicrograph of UHCS-1.8\% C-1.6\% Al showing coarse (100 $\mu$ m) martensite needles, and (b) SEM of UHCS-1.8\% C-1.6\% Al showing fine ( $<$ Hm) martensitic structure with undissolved proeutectoid Iron carbide particles.

at a magnification that is one hundred and twenty times higher than for the optical photomicrograph of coarse martensite (Figure 6a). The structure is seen to be ultrafine, with the martensite having a nondescript appearance and the background consisting of submicron-size spherical (undissolved) pro-eutectoid carbides.

Uitrafine martensite in a UHCS has remarkable compression properties [24,26]. Figure 7 compares thio compression engineering stress-strain curve of a UHCS$1.25 \% \mathrm{C}$ steel with a number of tungsten-cobalt alloys: The result is impressive: the fine martensitic UHCS is comparable to WC-12\% Co in strength and has a considerably greater compression ductility. The UHCS achieved an engineering strain in compression of $26 \%$ with an engineering fracture stress of $4690 \mathrm{MPa}$ (680 ksi). The curves also show that the UHCS absorbed large amounts of energy before fracture. This is an important characteristic for crashworthiness of structural members.

The tensile properties of UHCS have also been evaluated for different heat-treated conditions: bainitic, tempered martensitic, and fine pearlitic conditions. Examples are as follows. An ultimate tensile strength (UTS) of $1810 \mathrm{MPa}$ (262 ksi) with $18 \%$ elongation was obtained for a fine bainitic structure in a UHCS-1.0\% C-1.5\% $\mathrm{Cr}$ material [8]. A UTS of $1400 \mathrm{MPa}(190 \mathrm{ksi})$ with $25 \%$ elongation was obtained for a fine pearlitic structure in a UHCS-1.25\% C-1.6\% Al material. When an ultrafine pearlitic structure was developed, a UTS of $1655 \mathrm{MPa}(240 \mathrm{ksi})$ with $12 \%$ elongation was obtained for a UHCS-1.8\% C-1.6\% Al material [25].

The range in tensile properties that can be obtained with heat treatment of a fine-grained UHCS with spheroidized carbides is shown in Fig. 8 . In this figure the tensile strength is plotted as a function of elongation to failure for UHCS as well as three other common automotive steels - traditional mild steels, dual phase steels and HSLA steels. The figure shows that higher strengthductility combinations are. possible with UHCS than with the other steels.

A major deficiency of unalloyed ultrafine grained UHCSs is that they have low hardenability [8]. This is because grain boundaries are sources of nucleation of bainite and pearlite inhibiting the formation of martensite. It has been shown, however; that dilute alloying, can enhance the hardenability of fine-grained UHCSs [27]. The method of Grange [28] was used for determining the hardenability and the results are reported in Table 1. It can be seen that the critical diameter is only $6.9 \mathrm{~mm}$ for

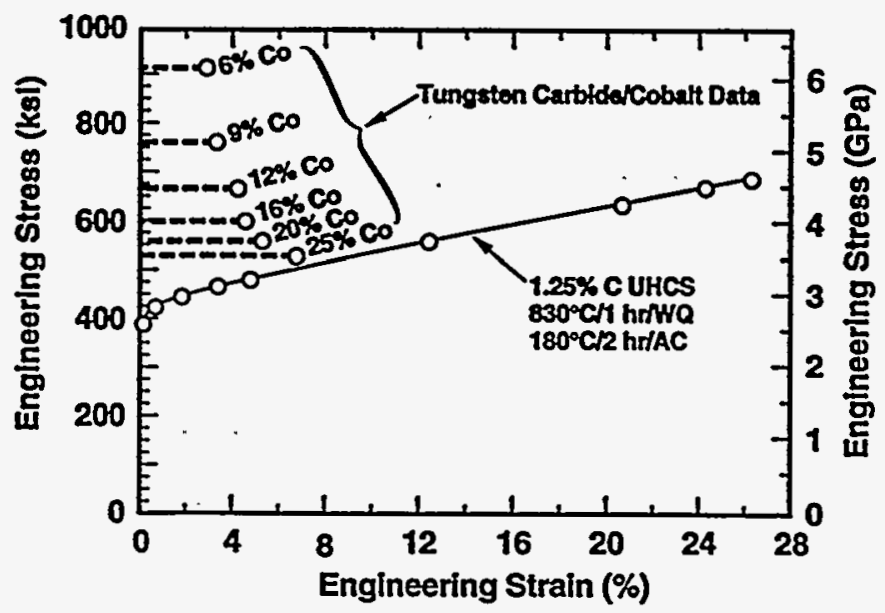

Figure 7. Engineering stress-engineering strain curve for a fine-grained martensitic structure UHCS-1.25\% C material tested in compression at room temperature. Comparison is made with a number of tungsten carbidecobalt alloys [25] 


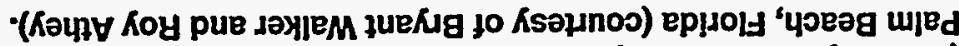

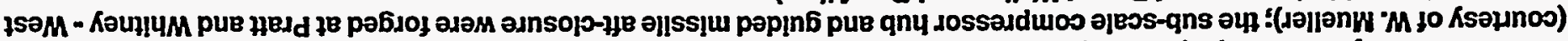

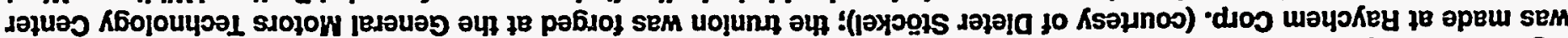

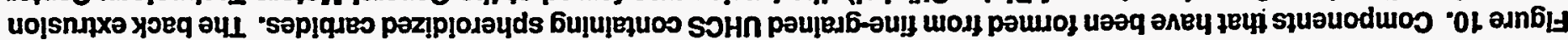

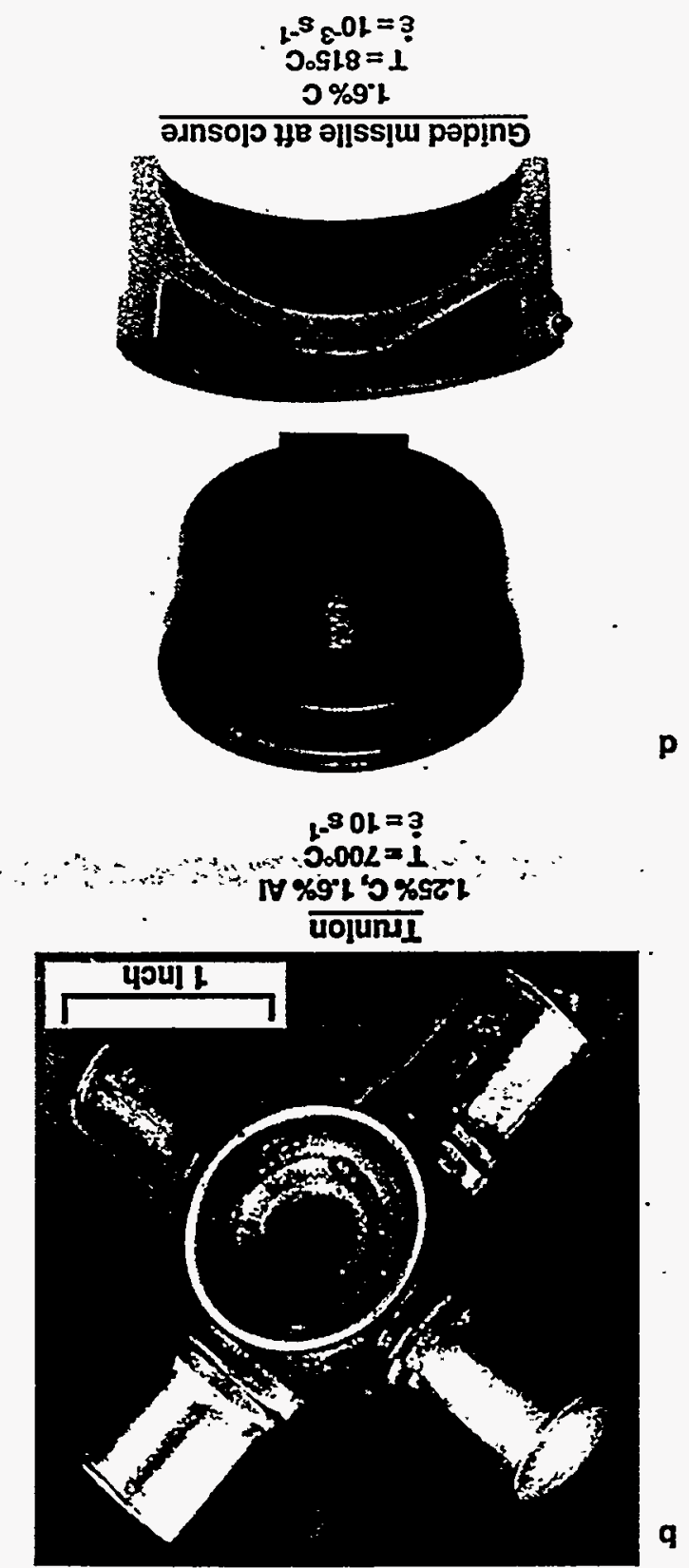

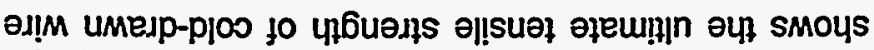

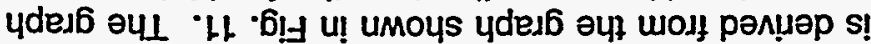

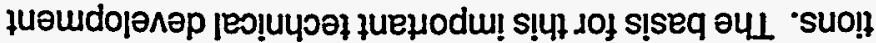

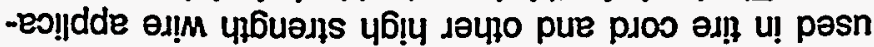

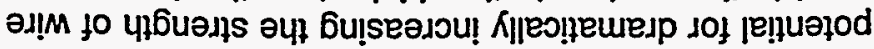

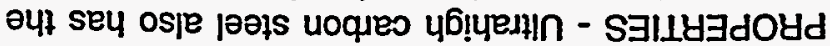

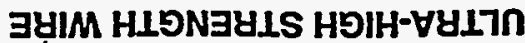

$\therefore$ *

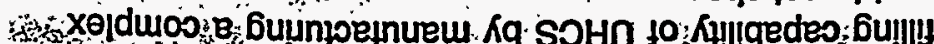

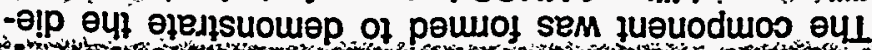

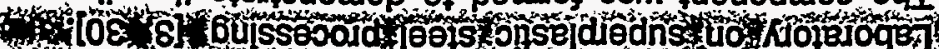

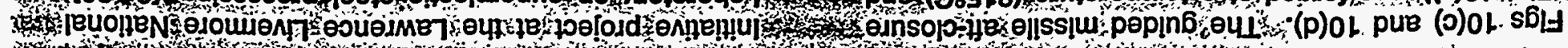

$1-5 \mathrm{~g}-\mathrm{OL}=3$

$0.0 S L=1$

I $\% 9^{\circ}$ เ ว $\%$ \%"เ

qny dossanduos
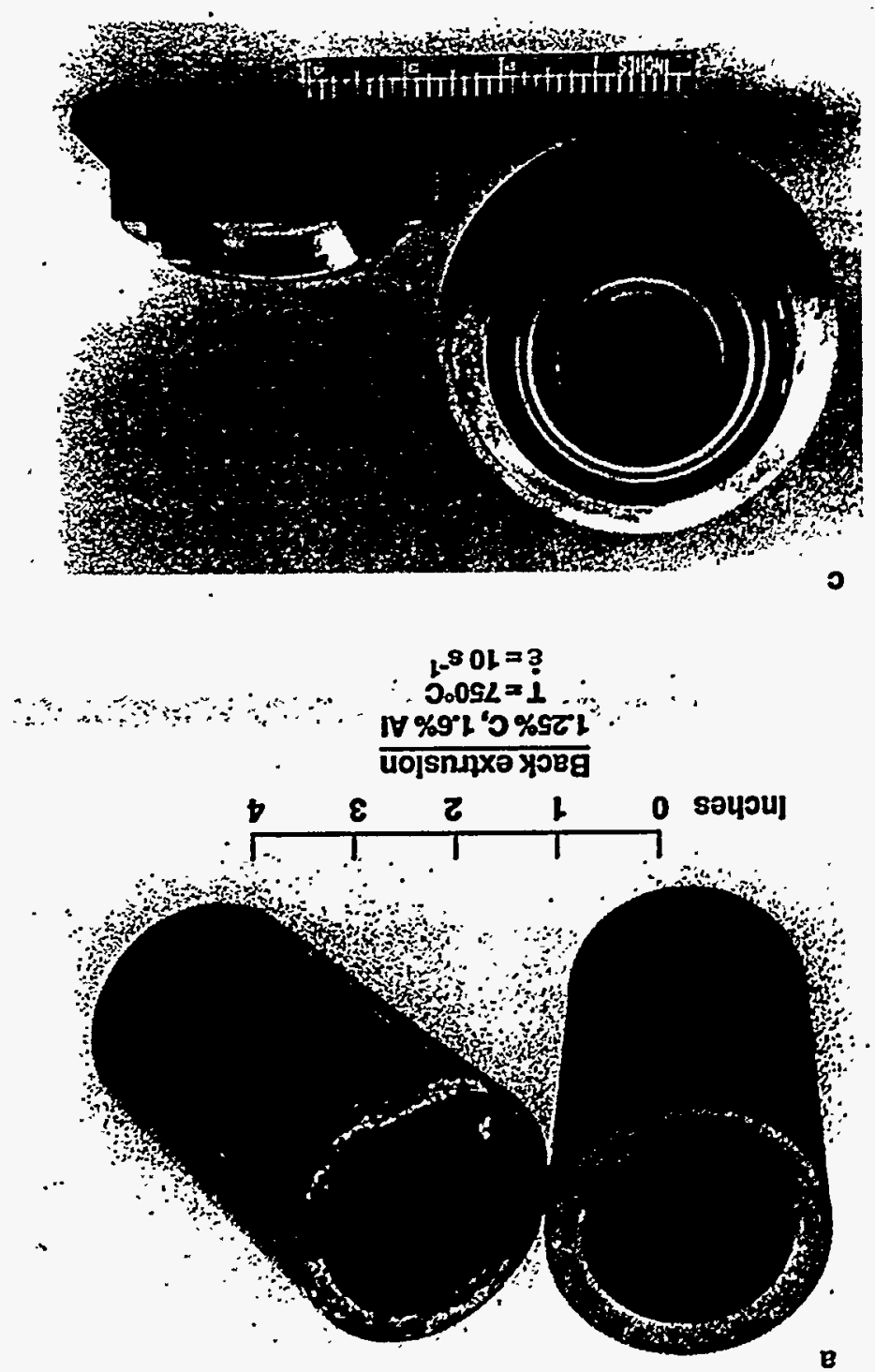

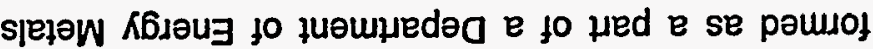

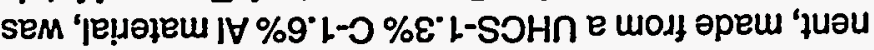

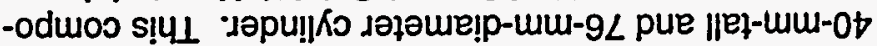

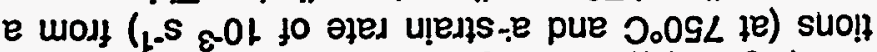

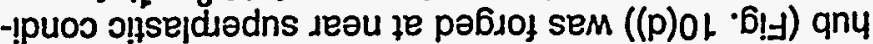

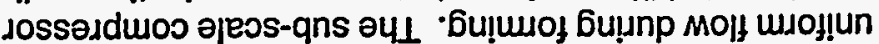

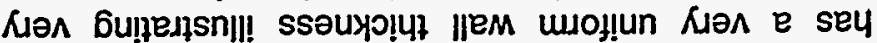

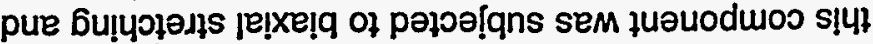

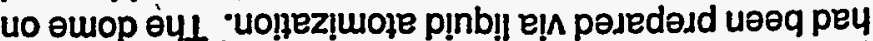
jeut siopmod ednłonis-oul! uod! pou!elqo sem jueuod

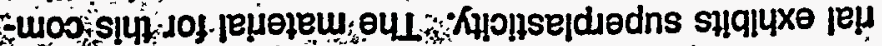

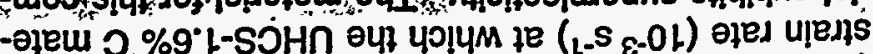




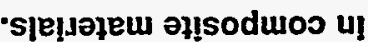

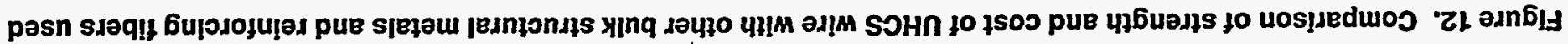

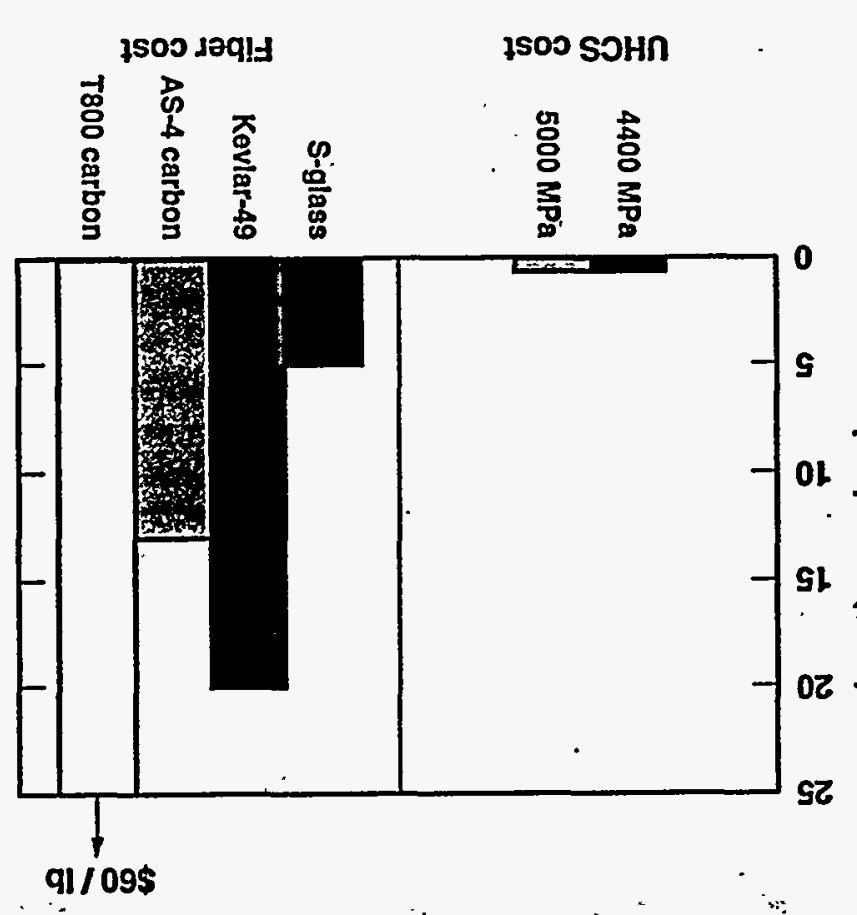

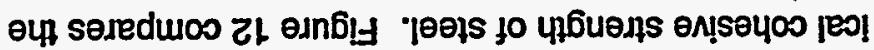

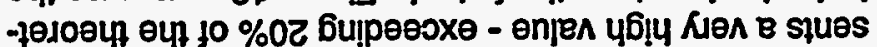

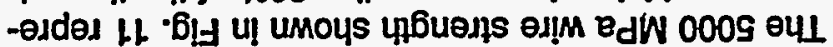
upbuens of seseedoul oneuredp

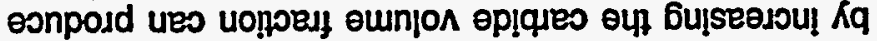

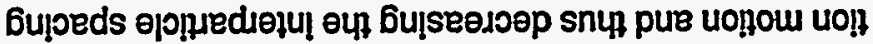

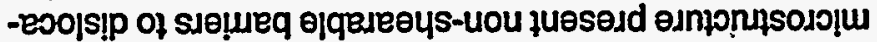

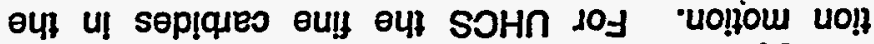

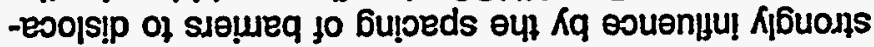

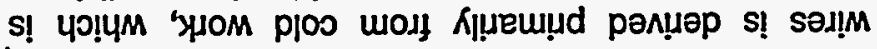

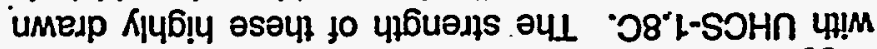

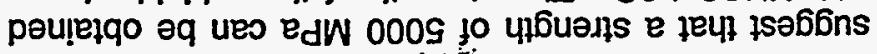

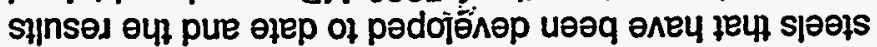

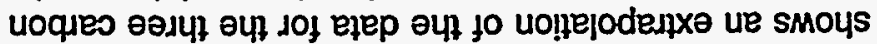

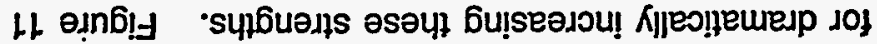

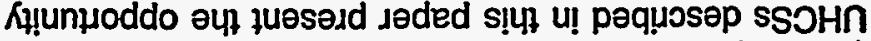

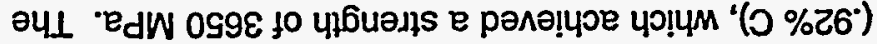

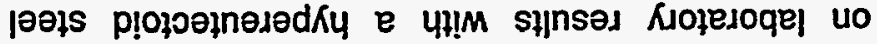

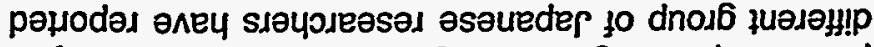
e Кำ

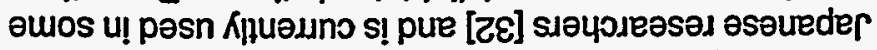

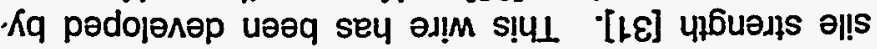

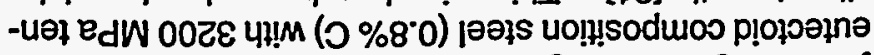

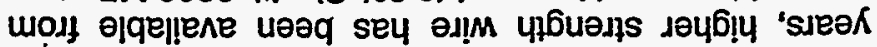

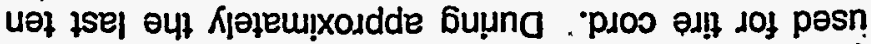

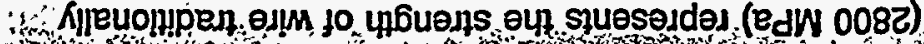
\% $0 \%$ \% le ul od elep oü

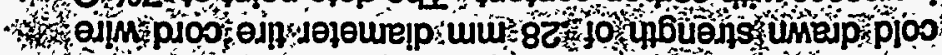

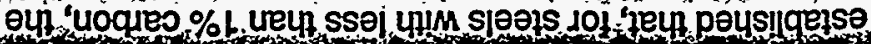
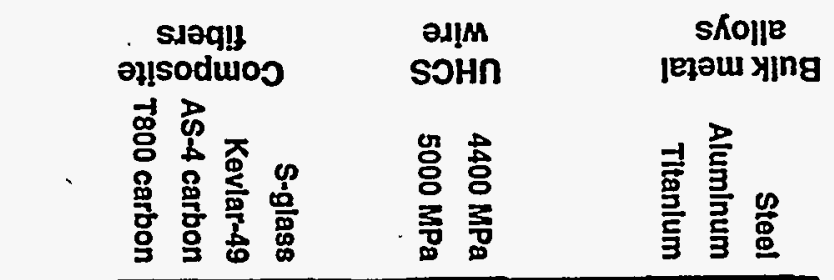

SOHก

[eวoแ ying

용 ثิ

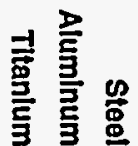

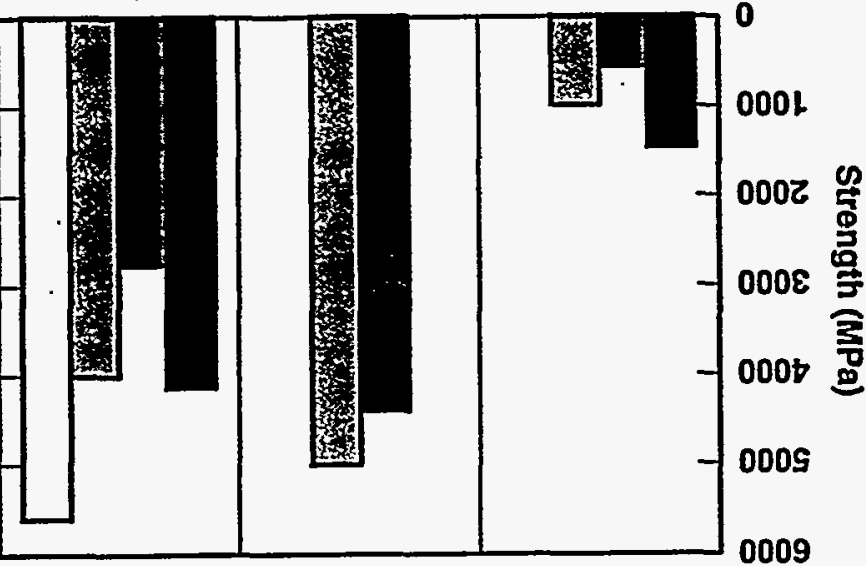

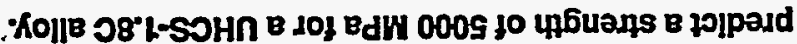

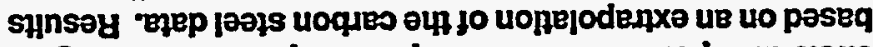

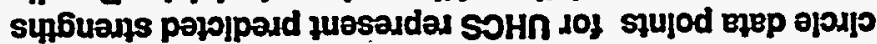

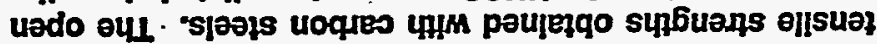

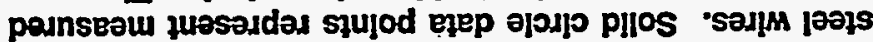

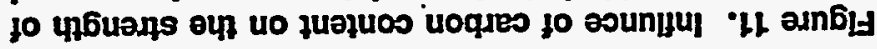

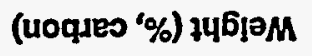

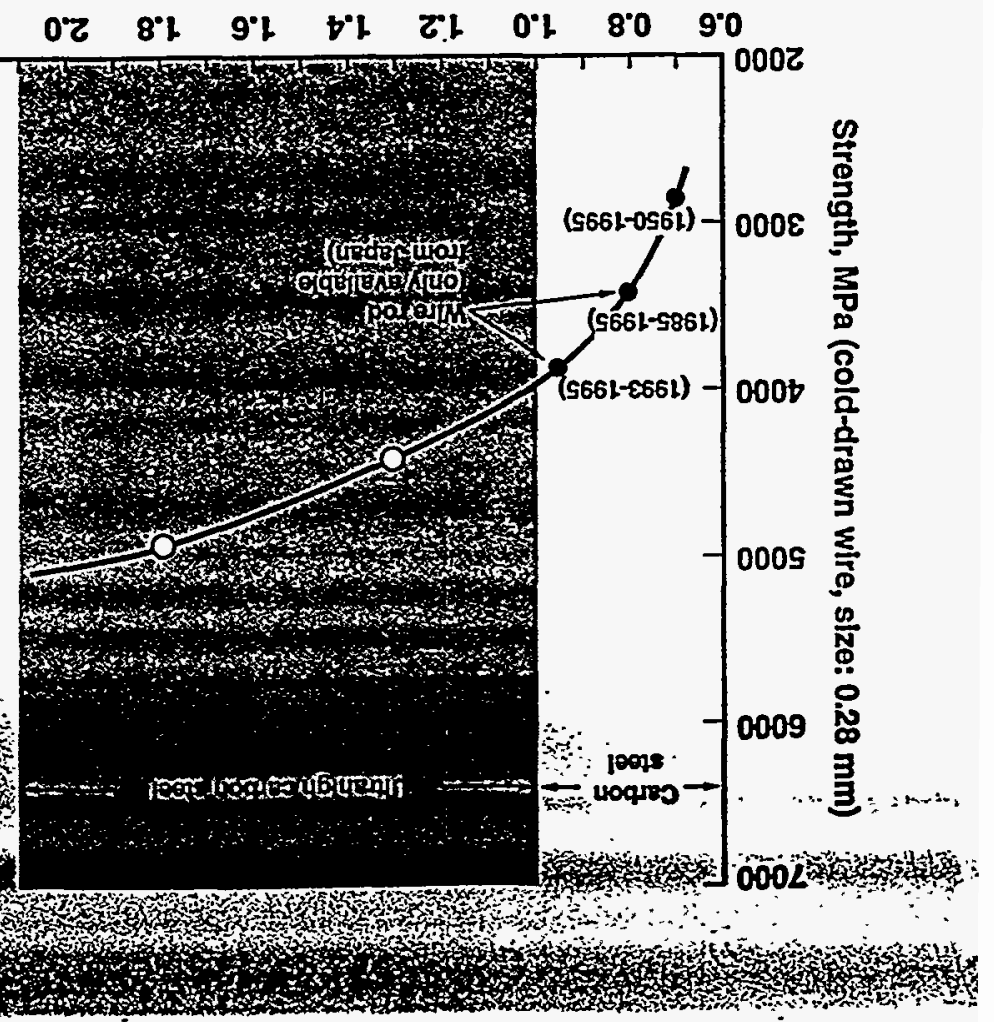


importantly the strength of these wires compares favorably with those of other reinforcing fibers such as S-glass, Kevlar-49 and carbon fiber. The figure also shows the cost of the reinforcing fibers; UHCS wire (with an estimated as-processed cost of $\$ .60 /$ pound) is significantly less expensive than other reinforcing fibers.

APPLICATIONS - As discussed above the ultrahigh strength wires produced from UHCS could be used in tire cord with significant increases in strength over current tire cord steels. These new materials could reduce the weight and rolling resistance of tires, which can result in significant increases in overall vehicle fuel economy. The annual energy savings in the United States resulting from a wire strength of $4700 \mathrm{MPa}$ (compared to a wire strength of $3400 \mathrm{MPa}$ ) is estimated at 520 million gallons of gasoline per year. Fuel efficient tires that result from higher strength tire cord can have a significant impact on the goals of the Partnership for a New Generation Vehicle, since $7.1 \%$ of the energy consumed in highway driving ( $4.2 \%$ for city driving) is lost to rolling resistance in the tires. In addition to tire cord, the higher strength wires resulting from UHCS could find automotive application in high strength hydraulic hose and fan belts.

\section{CONCLUDING REMARKS}

Ultrahigh carbon steels can have remarkable structural properties when processed to break up the proeutecoid carbide network and achieve fine ferrite grains with fine spheroidized carbides. These materials can find application as an ultra-high strength steel for sheet and plate applications. When processed for high room temperature ductility, UHCS can have a tensile ductility comparable to automotive high strength steels and plain, low carbon steels but significantly higher strength. It can also be made superplastic at intermediate temperatures and has demonstrated excellent die filling capability on a number of components during forging trials at intermediate temperatures. Furthermore, UHCS can be made hard with excellent compressive ductility and energy absorbing capability. The material also has unparalleled potential as ultra-high strength steel wire. A tensile strength of $5000 \mathrm{MPa}$ has been predicted for UHCS-1.8C. This material should find application for the reinforcing cord in an energy-efficient tire.

\section{ACKNOWLEDGMENTS}

This work was performed under the auspices of the U. S. Department of Energy by the Lawrence Livermore National Laboratory under contract no. W-7405-ENG-48.
Carbon Steels as Structural . Materials,, $10 \mathrm{M}$ 45.August (1993): $40-46$.

2. Sherby, O. D., et al., "Ultra High Carbon Steels" Journal of Metals (JOM) 37.June (1985): 50-56.

3. Strum, M. J., "Superplastic Steels: Joint LLNLIndustry Research," Energy and Technology Review, Lawrence Livermore Nat'l Lab. 1989: pp. 18-28.

4. Sherby, O.D., et al., "Superplastic Uitra High Carbon Steels", U.S. Patent 3,951,697: 1976.

5. Oyama, T., O. D. Sherby, and J. Wadsworth, "Divorced Eutectoid Transformation.(DET) Process and Product of Ultra High Carbon Steels", U.S. Patent, 4,483,618: 1984.

6. Oyama, T., et al., "Application of the Divorced Eutectoid Transformation to the Development of Fine-Grained, Spheroidized Structures in Ultra High Carbon Steels", Scripta Met. 18 (1984): 799-804.

7. Oyama, T., "Processing and Properties of Uitra. High Carbon Steels", Ph.D. Dissertation, Stanford University, 1983.

8. Avery, W. B., The Influence of Heat Treatment on the Microstructure and Properties of Fine-Grained Uitra High Cartion Steels", M.S. Disseration, Stanford University; 1982.

9. Yagi, Y., “Recent Trends and Future Tasks in Ironmaking and Steelmaking", Brussel: IISI, 1990.

10. Syn, C. K., D. R. Lesuer, and O. D. Sherby, "Influence of Microstructure on the Tensile Prop. of Spheroidized Ultra High Carbon Steel", Metallurgical Transactions A 25A. 7 (1994): 14811493.

11. Lesuer, D. R., C. K. Syn, and O. D. Sherby, "Fracture Behavior of Spheroidized Hyperetuectoid Steels", Acta Metall. Mater. 43.10 (1995): 3827 3835.

12. Baxter, D. F., "GM Develops a Superformable HSLA Steel", Metal Progress, Aug. 1977, pp. 44-48.

13. Sherby, O. D., et al., "Superplastic Ultra High Carbon Steels", Superplastic Forming, ASM, Metals Park, Ohio, 1985, pp. 32-42. 


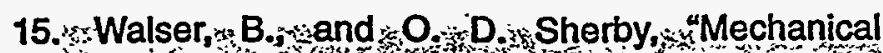
Behavior of Superplastic Ultra High Carbon Steels at Elevated "Temperature", Met. Trans.A A (1979): 381-386.

16. Ruano, O. A., L. E. Eiselstein, and O. D. Sherby, "Superplasticity in Rapidly Solidified White Cast Irons", Met. Trans.A 13A (1982): 1785-1792.

17. Eiselstein, L. E., et al., "Microstructure and Mechanical Properties of Rapidly Solidified White Cast iron Powders", National Bureau of Standards, Dec. 6-8, 1982, Gaithersburg, Maryland: 1982, pp. 245-251.

18. Kum, D.W., et al., "Microstructure and Superplastic Behavior of Eutectic $\mathrm{Fe}-\mathrm{Cr}$.and $\mathrm{Ni}-\mathrm{Cr}$ White Cast Irons", Met. Trans. A 18A (1987): 1703-1711.

19. Kim, W. J., et al., "Superplastic Behavior of Iron "Carbide", Scripta Metall. 23 (1989): 1515-1520.

20. Sherby, O. D., and T. Oyama, "Ultra High Carbon Steel Alloy and Processing Thereof", U.S. Patent, 4,533,390,:1985.

21. Sherby, O. D., et al., "Ultra High Carbon Steels Containing Ar", U. S. Patent 4,769,214: 1988.

22. Sherby, O. D., J. Wadsworth, and R. D.,Caligiuri, "Superplasticity in Iron "Base Alloys," $"$ Metals Handbook. ASM, Metals Park OH., 1988, vol. 14: pp. 868-874,.

23 Sherby, O. D., and J. Wadsworth, "Superplasticity in Iron-Based Alloys", Encyclopedia of Mat'ls Sci. and Eng. 1988, Suppl. Vol. 1 (1988): pp. 519-522.

26 Caligiuri, R. D., L. E. Eiselstein, and O. D. Sherby, "Properties and Applications of Ultra Hgih Carbon Steel Laminates", U. S. Army Materials Technol. Lab., Watertown, MA, 1990: pp. 499-525.

27. Sherby, O. D., and J. Wadsworth, Ultra High Carbon Steels," Encyclopedia of Mat's Sci. and Eng., Suppl., 1988, vol. 1: pp. 541-545.

28. Grange, R. A., "Estimating the Hardenability of Carbon Steels", Met. Trans. 4 (1973): pp. 22312244.

29. Wittenauer, J., P. Schepp, and B. Walser, "Application of Superplastic UHC Steel for Isothermal Forging of Machine Components", Aug. 1-4, 1988, Blaine, WA: TMS, Warrendale, PA, 1988: pp. 507-511.

30. U.S. Dep't of 'Energy, Office of Industrial Technologies, Office of Energy Efficiency and Renewable Energy, "Steel and Aluminum ,Energy Conservation and Technology Competitiveness Act of 1988", Annual Report of the Metals Initiative FY 1994, DOE/EE-0065

31. Shemenski, R. M., "Still the Right Stuff", Wire Joumal Intemational, 27,9 (1994): pp 70-80

32. Ochia, I., S. Nishida and H. Tashiro, "Effects of Metallurgical Factors on Strengthening of Steel Tire Cord", Wire Joumal Intemational, 26, 12 (1993): pp 50-61. 

